\title{
AO OLHAR-SE NO ESPELHO, A ENFERMEIRA NĀO TEM GOSTADO DA IMAGEM QUE AÍ VÊ REFLETIDA...
}

\author{
Dagmar E. Estermann Meyer *
}

\begin{abstract}
RESUMO - A partir de uma pesquisa realizada com docentes de um Curso de Graduação de Enfermagem, procuro situar e analisar os principais problemas que permeiam o ensino e a prática profissional da enfermeira (na percepção das depoentes), no sentido de contribuir para a reflexão acerca do papel da escola e de sua relação com o contexto social onde essa prática se inscreve.
\end{abstract}

ABSTRACT - This article uses data from a research of a faculty for an undergraduation Nursing School. I've tried to prove and analyse the main problems which in the teaching and professional practice of the nurse (as perceived by the professors interviewed), with the objective of contributing for the thinking about the role of social context on which this practice is situated.

\section{SITUANDO O TRABALHO}

Este artigo é parte de minha dissertação de mestrado, intitulada "Reproduzindo relaçōes de poder de gênero e de classe no ensino de Enfermagem", apresentada no curso de Pós-Graduação em Educação da Universidade Federal do Rio Grande do Sul.**

No contexto de uma investigação que discute o papel da formação moral e atitudinal no ensino de Enfermagem e sua vinculação com a necessidade de manutenção e reprodução das relaçōes de poder de gênero e de classe na profissão, este capitulo, denominado "O ensino, a profissão e seus agentes", teve por objetivo destacar os traços mais nf́tidos do quadro em que as docentes ouvidas retratam a Enfermagem e seu ensino, antes de adentrar na problemática específica da pesquisá em questão.

Sua reprodução na forma de artigo fundamenta-se no pressuposto de que o que se coloca como sendo características, valores, dúvidas e conflitos que permeiam a pratica pedagógica dessas docentes, pode, de certa forma, refletir 0 pensar e o fazer no cotidiano da docência de Enfermagem, em outros cursos nesse Pals. Aceitando-se esse pressuposto, penso que este estudo, embora não esgote a discussão sobre cada aspecto levantado, compōe uma imagem que pode contribuir para alimentar a reflexão acerca do processo de formação da enfermeira.

\section{2 "HÅ UMA BARREIRA SEPARANDO OS QUE ENSINAM A PRÁTICA E OS QUE PRATICAM A PRÁTICA....***}

A concepção de educação e desempenho profissional que parece implícita nas entrevistas sugere, a meu ver, nítida influência do pensamento liberal e do modelo tecnicista de ensino.

O pensamento liberal permeia colocaçōes como:

"... tanto faz ter um enfermeiro na instituição como não ter, a qualidade da assitência não melhora... tem um hospital que eu conheço, na época em que eu cheguei a Cuiabá, tinha uma enfermeira para 250 leitos. Hoje; tem quinze e o padrāo assistencial não mudou absolutamente em nada... quando é que o enfermeiro vai enfrentar esse desafio que é melhorar a assistência ?" (Laura)

A doutrina liberal fundamenta-se em cinco princípios básicos, quais sejam: o individualismo, a igualdade, a propriedade, a liberdade e a democracia (CUNHA ${ }^{2}$ ). Alguns deles parecem muito evidentes nos depoimentos. $\mathrm{O}$ individualismo, por exemplo, pressupõe que os indivfduos têm atributos diversos e é em função deles que alcançam posições vantajosas ou não. Pressupõe ainda que os indivíduos podem escolher voluntariamente o caminho que os leva ao sucesso ou ao fracasso, à riqueza ou à pobreza.

\footnotetext{
* Enfermeira, Professora Assistente do Departamento de Enfermagem da Universidade Federal do Mato Grosso.

* Pesquisa qualitativa em moldes que se aproximam da História Oral. Foi desenvolvida no Curso de Graduaçāo em Enfermagem da UFMT e os dados foram coletados em Jan./Fev. de 1990. As fontes de investigaçāo envolveram a consulta a documentos do curso e entrevistas semi-estruturadas com 15 docentes do mesmo. Para maiores detalhes ver: MEYER, D. "Reproduzindo relaçōes de poder de gênero e de classe no ensịno de enfenmagem". Porto Alegre, Faculdade de Educaçāo da UFRGS, 1991. Dissertaçäa de Mestrado.

****Almeida,
} 
CUNHA $^{2}$ argumenta que com este princípio a doutrina liberal não só aceita e justifica a sociedade de classes, mas fornece os argumentos que a legitimam. Segundo o princípio da liberdade, cada indivíduo é tão livre quanto o outro para atingir uma determinada posição social, em virtude de seus talentos e aptidões.

Assim, o problema parece estar na enfermeira que desempenha a função. Sua vontade e sua coragem de enfrentar desafios (ou a falta delas) quase que são determinantes no que diz respeito ao seu reconhecimento, enquanto categoria profissional. É como se a política de saúde do Paŕs, a política educacional, a situação de trabalhadora assalariada, as exigências do mercado de trabalho, o contexto sócio-econômico do Pals, etc., não interferissem no "bom" ou "mau" desempenho da enfermeira. Explica-se o "padræo de sucesso" ou "fracasso" através das caracteristicas individuais dos sujeitos, que independem do momento histórico e do contexto social onde tal padrão se aplica.

O modelo tecnicista de ensino tem permeado a Enfermagem desde sua estruturação enquanto profissão, se considerarmos a ênfase no fazer, na racionalidade, na eficiência e na produtividade, além do controle burocrático (evidenciado nos múltiplos formulários e manuais que preenchem o dia-a-dia da enfermeira) que têm estado presentes também na Enfermagem brasileira, bem antes da exaltação e incorporação desse modelo na educação do país dos anos 60-70. Isso explica, em parte, a aceitação e a eficiência com que as escolas de Enfermagem desenvolveram esse tipo de ensino. No curso em questão, soma-se a isso o fato de que ele integrou, desde sua criação, em 1976, o subprojeto "Ensino integrado e ensino programado do Projeto 10 - Operação Produtividade", concebido a partir de metas desenvolvimentistas que antecederam o "milagre econômico" brasileiro, subprojeto este que se vinculou explicitamente à tecnologia educacional, um dos pilares das chamadas inovações educacionais dos anos setenta.*

A influência tecnicista fica mais evidente quando se analisam as formas de organização e condução do ensino. Manifesta-se, em alguma medida, também nos depoimentos, quando estes apontam o "saber fazer" como caracteristica básica da área.

$$
\begin{aligned}
& \text { “...tem que saber aplicar na prática o } \\
& \text { conhecimento que recebeu..." (eva) } \\
& \text { “...se a gente conseguir, dentro da uni- }
\end{aligned}
$$

versidade, forma-se com competência técnica, já é um grande avanço..." (Júlia).

O que estas docentes apontam como problemas de ensino na Enfermagem não foge das questões que vêm sendo discutidas em quase todos os trabalhos, congressos, seminários, etc...., que enfocam, atualmente, a formação profissional da enfermeira: a dicotomia teoriaprática; o deslocamento do contexto sócioeconômico; a não vinculação com o político; a historicidade; a acriticidade; o tecnicismo (ênfase no fazer); a contradição que envolve o enfoque biologicista dos conteúdos e o discurso da prestação da assistência ao ser humano nos seus aspectos bio-psico-sócio-espiritual, a não habilitação da profissional para agir em função das necessidades de saúde da maioria da população; a ausência de um currículo coletivamente discutido e construído e que contemple um perfil profissional com base em marcos conceitual, referencial e estrutural claramente definidos, etc...

“...eu não vejo como, na nossa prática diária, vamos desenvolver o senso crítico do aluno, com o tipo de ensino que a gente faz; com o tipo de situação que o aluno vivencia, com o tipo de experiência que ele tem; com o tipo de literatura que a gente coloca à disposição do aluno. Nós colocamos essencialmente literatua técnica para o aluno, com literatura técnica você não desenvolve a crítica. Você nunca pede para o aluno analisar nada, você nunca pede para o aluno avaliar nada, você só pede para o aluno identificar... o discurso da sala de aula é técnico, totalmente técnico". (Paula)

"Se você pegar mesmo o plano de ensino, ele é baseado numa sociedade estruturada e que tem recursos. Então supõe-se que todas as mulheres farão pré-natal e serão atendidas no hospital, assim como as crianças, mas a nossa realidade é outra..."'(Laura)

Essas questões todas não são novas na Enfermagem brasileira e algumas delas nasceram juntamente com a implementação do primeiro curso de Enfermagem no Brasil, no Rio de Janeiro, em 1923. A dicotomia ensino/prática profissional foi institucionalizada quando se pretendeu que as enfermeiras atuassem em nível de saúde pública e os estágios curriculares se desenvolveram em nível hospitalar. De lá para cá, ela vem sendo reproduzida, assumindo diferen-

* GASTALDO, D., MEYER, D., BORDAS, M. "Ensino integrado: uma revisão histórico-crítica do modelo implantado no ensino superior da área de saúde no Brasil”". 1964/1978. Porto Alegre, 1990, mimeo. 
tes conformações em função dos momentos históricos e do contexto social em que se inscreve, mas, nunca foi resolvida. A meu ver, esta dicotomia tem inclusive uma duplá face, na medida em que o que se ensina a nível teórico, não pode ser aplicado nem mesmo nos estágios, em virtude das condições da maioria dos campos (de estágio) onde esse aprendizado se desenvolve. Já começa nessa instância a ser avaliada a "criatividade" da estudante, o que, em outras palavras, nada mais é do que "improvisação diante da falta de material adequado" de acordo com os roteiros de avaliação vigentes. $O$ fosso existente entre o ensino e a prática profissional, a partir dar, é apenas ampliado e assume diferentes características.

Inicia-se com o objeto de trabalho que, no ensino, é apresentado como sendo fundamentalmente o cuidado ao paciente/cliente e, na prática, tem sido predominantemente a gerência dos serviços e o controle de pessoal e material. Manifesta-se, na pretensão teórica da prestação da assitência de Enfermagem em nível bio-psico-sócio-espiritual ao indivíduo, famnia e comunidade, atraves do "Processo de Enfermagem", fruto das teorias de Enfermagem elaboradas a partir da década de 70 com o intuito de cientifizar a profissão e estabelecer um saber próprio da área. Apesar de reiteradas tentativas e adaptações, o "Processo de Enfermagem" tem sido passivel de aplicação, quase que exclusivamente em alguns Hospitais Universitários, que não retratam a realidade das Instituições de Saude brasileiras. Embora as docentes entrevistadas tenham reconhecido, com unanimidade, que a enfermeira não tem tido fundamentação teórica suficiente, nem condiçöes práticas, para prestar assistência de Enfermagem nessa amplitude nem mesmo ao nível do ensino, nos estágios curriculares, este $\varepsilon$ um objetivo educacional presente na totalidade dos planos de ensino analisados no curso em questão*, desde sua criação até os dias de hoje. Nesse sentido concordo com ALMEIDA' quando coloca que "o ensino é caracterizado como o paradigma do saber, esquecendo-se que $e$ no trabalho que se devem buscar os elementos do saber. É no desenrolar do cuidado de Enfermagem, no qual se opera diretamente com ó objeto - o doente - e onde se dão as relações técnicas e sociais que está a essência do saber. $O$ distanciamento entre ensino e prática cada vez é mais polar. Há uma barreira separando os que ensinam a prática e os que praticam a prática".

Nesse contesto de ensino, como as docentes percebem e descrevem a sua prática enquanto agentes formadoras?
Os relatos mencionam tentativas não formalizadas e, na maioria das vezes, levadas a cabo por pequenos grupos 'ou indivíduos isolados, no sentido de encontrar formas mais criticas, mais abrangentes e mais enraizadas no contexto sócio-econômico-cultural para a condução do ensino. No entanto, prevalecem os problemas gerados no âmago da trajetória histórico-social da profissão e das politicas educacionais que têm norteado o ensino brasileiro e, mais especificamente, da Enfermagem: o despreparo para trabalhar os conteúdos, vinculando-os a uma sociedade concreta e historicamente determinada; as contradições entre o discurso e o vivido; a ênfase no fazer técnico em detrimento do est'mulo à procura do conhecimento, ao raciocínio, à análise da prática e à participação crítica e política; a inadequação do nível de exigência do ensino ministrado à clientela que o procura; a busca da valorização do domínio do conhecimento técnico, sem que se tenha clareza dos limites e da natureza do "conhecimento da Enfermagem".

Vejamos alguns exemplos:

“...eu acho que o professor, ainda hoje, vai pra sala de aula com o conhecimento na ponta da língua. Ele chega lá, despeja tudo em cima do aluno. Eu acho que ele consegue trabalhar muito pouco... de forma estimulante, de forma que o aluno participe efetivamente do aprendizado dele" (Carla).

"...nós temos um bom número de professores ainda em dúvida quanto ao exercício da Enfermagem. Agora imagina com relação ao ensino de Enfermagem ! ..." (Mariana) "...o que a gente tem hoje é uma contradição dentro do próprio curso, nas diversas unidades (disciplinas) pelas quais o aluno passa, inclusive em relação a esse nível de cobrança de conhecimento... algumas unidades cobram o saber de Enfermagem, outras ensinam e cobram o saber médico". (Denise).

A respeito da prática pedagógica vigente nos cursos de Enfermagem, GERMANO 4 conclui que "E, portanto, a prática bancária, conservadora, e não a prática problematizadora, questionadora, que se fez presente na formação dos profissionais e, nessa perspectiva... é mais um elemento a contribuir na reprodução das desigualdades sociais".

* Analisados 125 planos de ensino, referentes ao período de 1980/90. 
A aluna aparece nesses depoimentos como um dos elementos responsáveis pela não efetivação do ensino nos moldes propostos. MELLO $^{\mathfrak{B}}$ chama a atenção para o fato de que, entre "culpar" a aluna ou colocar a própria escola em questão, é a primeira alternativa que acaba recebendo maior adesão das professoras.

Assim, lê-se nos depoimentos:

"...no início do semestre você recebe $99 \%$ de mulheres, mas independente disso, são mulheres com um nível de escolaridade muito ruim,... não sei se o nível de escolaridade delas é ruim porque são mulheres ou porque, de repente, vêm de um nível sócioeconômico baixo". (Ana)

"...o aluno, que está fazendo o curso de Enfemiagem, não tem determinados conhecimentos que são básicos para qualquer aluno que faz um curso universitário... o que acontece é que o que temos proposto, em termos de ensino, é para um outro tipo de alunos que temos. Então o professor fica insatisfeito, porque ele propõe uma coisa que ele não consegue executar". (Carla)

FORQUIN ${ }^{3}$, numa revisão dos estudos que buscam explicar as desigualdades no êxito escolar e sua relação com a classe social de origem, faz uma reflexão que considero muito pertinente ao caso dos cursos de graduação em Enfermagem no Brasil: "Los estudiantes dos medios populares tiendem as concentrar-se en los canales 'faciles' o poco selectivos, que son tambiém los menos rentables socialmente, mienstras que los estudiantes procedentes de los medios privilegiados escojen con más frecuência, los canales donde la selección es más severa, como la física e la medicina. La auto-selección que constituye la elección de canales más faciles y menos 'rentables' socialmente, serve asi de máscara, de repetidor y de 'edulcorante' para la desigualdad ante la selección".

Assim, quando a(o)s depoentes referem que a clientela que procura o curso não preenche as suas expectativas enquanto docentes, percebese ate alguma clareza do porquê isto acontece, mas não se vai fundo nessa questão e muito menos se vai além dela.

A fala de Ana, quando se refere ao "nível de escolaridade" das alunas, remete a outro plano da análise, qual seja, o do cruzamento das categorias gênero e classe social que se dá na Enfermagem. Numerosos estudos têm demonstrado que a socialização feminina, com ênfase na importancia da famnia juntamente com o pressuposto de que este é o lugar da mulher, te- ve e tem um grande impacto nas profissōes sexualmente discriminadas. Esta socialização tem um importante papel na escolha profissional da mulher e acaba por encaminhá-la para determinados tipos de profissões/ocupações entendidas como adequadas ao seu ingresso no mercado de trabalho, em função dos papéis designados a ela (mulher) na esfera privada. Estas profissōes/ ocupaçōes são geralmente desvalorizadas e mal remuneradas e, portanto, pouco atraentes para os homens, o que contribui para que elas se transformem em cursos de "fácil entrada" e menos concorridos nos vestibulares. Se considerarmos ainda que a Enfermagem vem se proletarizando e a qualidade de ensino a que as camadas menos favorecidas da população têm acesso, não me parece difícil entender porque as alunas de Enfermagem têm um "nível de escolaridade baixo".

\section{3 "... O PAPEL DO ENFERMEIRO HOJE, NĀO ESTÁ CLARO NA PRO- FISSĀO..."}

Em relação à representação da profissão, o que se evidencia na quase totalidade dos depoimentos é que as expectativas que essas docentes tinham quando ingressaram no curso, foram se modificando - negativamente - ao longo dos semestres e o que se esperava ao ingressar na prática profissional, mesmo com essas modificações, não era passível de realização.

As referências à falta de "status" social e à desvalorização profissional e salarial aliados à característica de profissão predominantemente feminina, sem autonomia na tomada de decisões, submissa aos poderes institucional e médico, sem limites de atuação estabelecidos e funções indefinidas, mostram, de certa forma, a incorporação do discurso mais crítico veiculado nos últimos anos, mas denotam também um sentimento de impotência e pessimismo diante dos rumos da profissão.

Parece-me que persiste a dificuldade de fazer a vinculação entre o que se dá "dentro" da profissão com o que está "em volta dela" e que na verdade a atravessa, e o ato de isolá-la no tempo e no espaço, leva a uma circularidade nas discussões, que se evidencia nos depoimentos até aqui registrados. O ensino é apolítico, ahistórico e desvinculado da realidade, a(o) docente sente que não tem preparo teórico, prático e político para fazer um ensino diferente, as alunas não estão preparadas para o ensino que se planeja e oferece, e a concepção que as pessoas têm da profissão acaba por refletir tudo isso. Paula, num determinado momento, coloca lenfaticamente: "Eu acho que a gente estuda at $\epsilon$ 
demais para o que vai fazer depois".

Nesse sentido e interessante o que se verifica quando se analisa documentos que norteiam o ensino, especialmente os planos de ensino, que refletem (ou deveriam fazê-lo) os conteúdos da formação profissional. Busca-se a transmissão massiça de conhecimentos técnicos, numa abordagem predominantemente biologicista e essa problemática da profissão não aparece registrada explicitamente, seja em termos de conteúdo, seja nos objetivos que pretendem ser alcançados.

Registro nos depoimentos:

"Hoje, eu sei muito mais, senão o que a Enfermagem faz, mas pelo menos o que ela deveria fazer. Eu tenho muita consciência disso, eu não vejo a profissão como a maioria das pessoas está vendo hoje... num ritmo de decadência, de queda. Se isso acontece, eu acho que é muito mais pelas pessoas que procuram, que estão atuando na área, do que pelas características da profissão em si..." (Denise)

"...eu vejo a Enfermagem como uma profissão que está distanciada da realidade no nosso contexto". (Ione)

“...hoje a profissão está seguindo uma linha muito mais de busca do saber do que mesmo do fazer... por um lado eu acho até bom porque vem contribuir para a profissionalização do enfermeiro, mas por outro lado a prática está ficando muito distanciada e isso... é uma problemática inteira que a profissão tem..." (luiz)

SILVA $^{8}$ ao analisar as representações sobre a Enfermagem, veiculadas principalmente em nível da Associação Brasileira de Enfermagem, através da Revista Brasileira de Enfermagem, assim como suas definições, diz que elas refletem "uma enfermagem abastrata, idealizada e irreal, independentemente de um espaço e um tempo concretos" porque não a mostram, enquanto prática social historicamente determinada, permeada de heterogeneidade e contradiçōes.

Eu diria que nas representações das docentes deste estudo, até mesmo em função da discussão de textos como o acima citado, manifesta-se uma tentativa de ir alem dos limites impostos pelo que tem sido concebido como Enfermagem. Isso, no entanto, não tem sido transportado para as discussōes ao nível das salas de aula.

O entendimento da profissão enquanto heterogênea e contraditória manifesta-se nas entrevistas principalmente em relação a dois pontos: a) a divisão intelectual/manual do trabalho e a parcelarização das atividades pelas diversas categorias que integram a equipe de enfermagem; b) à falta de clareza quanto ao seu objeto de trabalho e a não delimitação de funções.

MELO $^{5}$, NAKAMA $^{7}$, e ALMEIDA ${ }^{\prime}$ discutem a divisão social do trabalho e seus desdobramentos na Enfermagem, analisando-a no contexto do processo capitalista de produção, onde ela (a divisão) se consolida. Assim analisada é possível compreendê-la - no que diz respeito à definição de espaços/funções da medicina e Enfermagem, e principalmente, à hierarquização que se desenvolve na equipe de enfermagem - como produção da divisão manual/intelectual do trabalho, que no capitalismo, reforça as relaçōes de dominação/subordinação entre as classes sociais. A Enfermagem moderna nasce reproduzindo a divisão social do trabalho entre duas categorias distintas: a "lady-nurse" e a "nurse". Essa divisão foi se consolidando e ampliando, em termos de categorias profissionais envolvidas e tem sido percebida "pelos enfermeiros, na maioria das vezes, como tradição, como condição necessária e harmoniosa para uma maior produtividade do trabalho e, outras vezes, como indesejável e prejudicial" (BARROS apud MELO ${ }^{5}$ ).

Isto se expressa nos depoimentos a seguir:

“...os problemas relacionados a essas categorias que existem em função de uma política de trabalho do pars e que de certa forma nós somos obrigados a aceitar... trabalhamos contra, na medida em que nos qualificamos, que mostramos trabalho e que ocupamos um espaço... prá que o enfermeiro seja valorizado". (Rita)

"...eu acho que o trabalho tem que ter uma divisão técnica... porque tudo tem divisão. Se você for ver na área de engenharia, por exemplo, tem aquele que comanda, tem o que executa e tem o que planeja, então na Enfermagem tem que ter tambem. Eu acho que para o enfermeiro fica o comando das atividades de Enfermagem..." (Denise)

Na Enfermagem, a dimensão manual do seu trabalho tem sido entendida como um dos fatores geradores de sua desvalorização social. Nesse sentido, a fragmentação das atividades por diferentes categorias, com graus de preparo e escolarização diversificados significou o deslocamento da enfermeira para uma função de direção e controle dos serviços da assistência e da equipe de Enfermagem e possibilitou-lhe, em função da separação concepção/execução, assumir o papel de intelectual da área. 


\section{Diz Carla:}

“...em nossa sociedade o que é manual não ê valorizado... tem valor o que é intelectual, e isso e uma coisa que tem pesado, que tem influenciado a nossa profissão na busca de valorização... dar eu achar ate que a gente tem valorizado mais determinadas coisas em detrimento de outras que me parecem que são básicas na profissão, por exemplo, a questão do cuidado..."

Para ALMEIDA', o fato da prática de Enfermagem não estar sendo exercida pela enfermeira em toda sua extensão, determinou perda de espaço profissional, pois, a partir do momento em que passou a ocupar cargos de chefia, iniciou-se o seu processo de marginalização na prática da saude, uma vez que ela se distanciou do paciente, do pessoal auxiliar e das atividades dirigidas diretamente ao objeto de saude - o paciente/cliente.

No que se refere à delimitação do espaço e funções de cada categoria na Enfermagem, especialmente das enfermeiras, esta tem sido muito diff́cil na prática, devido "à crise de identidade" destes elementos. Apesar da regulamentação em lei (Lei no 7498 de 25/06/86), que estabelece as atividades privativas da enfermeira, da técnica, da auxiliar de Enfermagem, isto não vem se concretizando na prática, onde todos fazem praticamente tudo, ficando a enfermeira vinculada prioritariarnente às atividades administrativas e burocraticas.

Referindo-se à Lei do Exerćcio Profissional, Lenir Marques* comenta que já se encontrava defasada quando de sua aprovação (foi aprovada 13 anos depois de proposta) e apesar disto, persistem dificuldades imensas para sua implementação. Enfatiza que as funções da enfermeira năo podem e nắo såo cumpridas nas condiçōes de trabalho vigentes. Nesse sentido, a enfermeira vem sendo conivente com o exercício irregular da profissåo nåo 86 porque assume funçōes que nảo såo suas, como também porque delega suas proprias funçoீes e continua a preparar atendentes de enfermagem, categoria extinta na referida Lei. O depoimento de Silvia $C$ bastante pertinente ao que foi dito acima:

"...o papel do enfermeiro hoje, não está claro na profissåo... a nivel dos hospitais particulares a gente já sabe, o enfermeiro está lá para vigiar os atendentes e auxiliares e tomar conta de um monte de chaves. Nos centros e postos de saude ele divide o trabalho com o médico... e muitos profissionais acham que se valorizam por estarem substituindo médicos".

$\mathrm{Na}$ verdade, cabe refletir aqui em que medida 0 processo de formação encaminha a enfermeira para esta direção, uma vez que, não tendo claros seus limites concretos de atuação, o que é inculcado e cobrado como sendo responsabilidade profissional significa, na prática, exatamente isto: cobrir as deficiências de todos os serviços e de todos os profissionais envolvidos no atendimento do paciente/cliente, porque este não pode ser prejudicado. Não pode e não deve mesmo; mas porque é justamente a enfermeira que deve responder por isso ? A associação que faz entre as funções profissionais da enfermeira com aquelas "de responsabilidade da mulher" em casa, pode fornecer alguns elementos para compreender melhor esse aspecto. Isso porque, na famnlia, cabe essencialmente à mulher o atendimento das necessidades básicas de manutenção e reprodução da vida. Para cumprir esse papel, a mulher assume uma gama de responsabilidades e procura responder até por situaçōes que, na verdade, estão fora de seu alcance. Laura:

Com relação à "crise de indentidade", diz

\begin{abstract}
“... essa crise de indentidade vem em função da perda de espaço, perda de competência, perda de postura pessoal e profissional... $O$ enfermeiro se afastou muito da assistência, ficou muito mais atrás de uma mesa, na parte administrativa, sem a visão do assistencial e isso foi ruim porque ele perdeu o comando de sua propria equipe..."
\end{abstract}

SILVA ${ }^{*}$ analisa essa crise de identidade como sendo ideológica, porque a identificação com o cuidado direto (o que vem no bojo do depoimento de Laura), ou seja, com a Enfermagem do passado, sem divisão técnica entre cuidados exercidos por diferentes agentes, significa um descompasso entre as transformaçōes ocorridas e as concepções tradicionais e cria uma situação ambigua para as enfermeiras, identificada como sendo um problema de indefinição de papeis. Para $\operatorname{SILVA}^{*}$, a superação ideologica dessa indefinição só se dará pelo resgate das rafzes históricas dessa categoria profissional e trabalhando-se com os dados da realidade concreta de um momento histórico determinado, o que significa reconhecer as trans-

* Ex-Preaidente do COREN-RS em mesa redonda "Isonomia Salarial e Legislaçāo Trabalhista" proferida no V Enf. Sul, Porto Alegre, jund/1990. 
formações pelas quais passou a Enfermagem do pre-capitalismo ao capitalismo e detectar as suas características básicas na sociedade brasileira atual. Isso, para ela, implica em reconhecer que as atividades administrativas e de ensino constituem o objeto de trabalho por excelência das enfermeiras hoje, no Brasil, nảo sendo a negação desse fato que vai garantir a preservação da categoria. Já NAKAMAE ${ }^{7}$ defende que essa superação ideológica deve implicar tambem num resgate ou numa conquista do cuidado direto, porque renunciar a ele seria "a submissão final do enfermeiro ao capital, com a mutilação de sua competência técnica e, em conseqüência, a perda de sua especificidade profissional".

Não é meu objetivo, neste trabalho, defender uma ou outras das direçōes apontadas acima, o que me importa registrar é que a recuperação ou aquisição da identidade profissional passa necessáriamente pela compreensão do processo de trabalho da enfermeira, ou seja, pela consciência das ações desempenhadas no cotidiano. A enfermeira não pode continuar alienada da própria prática (no sentido marxiano do termo).

A docente de enfermagem, de modo geral, não poupa críticas à enfermeira no exercício da profissão. A compreensão de que ela $\epsilon$, em ultima instância, também um produto do processo de formação, ou seja, do próprio trabalho docente, começa a despontar em alguns depoimentos. Eu diria que, ao olhar-se no espelho, a enfermeira não tem gostado da imagem que al vẽ refletida. Os contomos dessa imagem, descritos com mais r cuidado direto; o caráter submisso e tarefeiro do seu fazer; a falta de ousadia profissional; o apego à burocracia, à regras e ao caráter gerencial da assistência; a busca da valorizaçāo através de funções que não lhe competem; a falta de engajamento político; a falta de visão crítica em relação ao contexto sócio-económico onde sua prática se insere.

Vejamos o que dizem os depoimentos:
"O enfermeiro ainda está muito bitolado... ele ainda nảo tem autonomia pra desenvolver sua profissão, ele está vinculado a atividades restritas... ele tem muita dificuladade para desenvolver a autonomia..." (Silvia)

"...eu acho que pra enfermeira ainda falta aquela ousadia de querer fazer alguma coisa, independente dessa coisa só técnica..." (Júlia)

"...a visão que o enfermeiro passa 6 mais daquele profissional que tem mil qualidades... mais voltado por lado do comportamento do que do tipo de reconhecimento que ele precisa para exercer essa profissão" (Tấs)

Aqui se vê quanto a própria docente tem estado envolvida no "clima" de crise, de questionamentos e até mesmo de pessimismo que perpassa a profissão, uma vez que ela e o curso não existem em abstrato, mas se inserem concreta e ativamente numa realidade histórica e socialmente determinada.

\section{E DAI ?}

Analisadas no seu conjunto, estas falas desvelam conflitos ondsualmente se pressupōe consenso, iluminam a distância e/ou proximidade entre o discurso e o vivido e redimensionam os efeitos de currículos, planos de ensino e regulamentos.

Mais do que isso, porem, remetem para uma reflexão acerca do papel da escola e de sua relação com o contexto social onde a prática da Enfermagem se inscreve.

Nessa perspectiva, conhecer a força de trabalho docente (e suas dificuldades e conflitos) $E$ essencial para saber que ensino está sendo executado. Só então será possível entender porque tantas tentativas de transformação até hoje propostas, não tem saído do papel e quando o fizeram, não interferiram significativamente na realidade que se pretendeu mudar.

\section{REFERÊNCIAS BIBLIOGRÅFICAS}

1 ALMEIDA, M.C. e ROCHA, J. $O$ saber de enfermagem e sua dimensáo prática. Sảo Paulo: Cortez, 1986.

2 CUNHA, L.A. Educaçāo e desenvolvínento sacial no Brasil. 6 ed. Rio de Janeiro: Francisco Alves, 1980.

3 FORQUIN, J.C. "El enfoque sociolbgico del exito y del fracasso escolares: desigualdades de erito escolar y origem social'. Educacion y Sociedade, Madrid, (3): 177-224, 1985.

4 GERMANO, R. Educação e ideologia da Enfermagem no Brasil. 2 ed. Sāo Paulo: Cortez, 1985.
5 MELO, C. Divisão social do trabalho e Enfermagem. Sāo Paulo: Cortez, 1986.

6 MELLO, G.N. Magistério de 1 Grau - da competéncia ao compromisso polfrico. 7 ed. São Paulo: Cortez, 1987.

7 NAKAMAE; D. Novos covinhos da Enfermagem. Sāo Paulo: Cortez, 1987.

8 SILVA, G.B. Enfermagem profissional - andlise critica. São Paulo: Cortez, 1986. 